\title{
New Roads and Old Promises of Music Sociology
}

\author{
SMUDITS A. (ED.) (2019) ROADS TO MUSIC SOCIOLOGY. WIESBADEN: SPRINGER. 158 P. ISBN 978-3-658- \\ 22278-9
}

\author{
Nail Farkhatdinov \\ PhD, Senior Research Fellow, Centre for Fundamental Sociology, \\ National Research University-Higher School of Economics \\ Address: Myasnitskaya str., 20, Moscow, Russian Federation 101000 \\ E-mail: nfarkhatdinov@hse.ru
}

Musical sociology is perhaps the only discipline among the many sociologies of the arts that attempts to construct its identity and to propose a kind of general research program. There is a set of common theoretical and methodological problems which have been discussed for the last couple of decades which can be traced back to the studies of Max Weber and Theodor Adorno, and are considered to be the classics of the theoretical sociology of music.

The collection Roads to Music Sociology provides us with the opportunity to review the problems and to see how the research agenda of the discipline has changed and advanced during the last several decades. However, the main assumption common to many scholars still remains unquestionable. It is the rejection to give any essential definition of music. The contributors do not define music. Instead, they suggest using the conventional definitions of music circulated in society. These definitions are usually broader than the ones accepted by musicologists and musicians themselves; this fact is a traditional point of tension between sociology and music. Instead of speaking of one Music (with a capital letter M, i.e., Music as art), sociologists study "musics", exploring the social hierarchies that make one kind of music art while neglecting the rest.

The collection is edited by Alfred Smudits, and is part of the series Music and Society. The formal aim of the volume is to celebrate the 5oth anniversary of the Department of Music Sociology at the University of Music and Performing Arts in Vienna, Austria. To celebrate the Jubilee in 2015, the Department organized a two-day conference entitled "50 Years of Music Sociology in Vienna. Historical Roots. Current Approaches. Future Perspectives". The second purpose of the meeting, as indicated by Alfred Smudits in his "Introduction", was to reflect on the contribution of the Austrian musicologist, Kurt

* The results of the project "Between Political Theology and Cognitive Sciences: New Alternatives, New Challenges, or New Resources for Social Theory” carried out within the framework of the Basic Research Program at the National Research University Higher School of Economics (HSE) in 2020, are presented in this work.

1. 50 Years of Music Sociology in Vienna: Conference Program. Available at: https://www.mdw.ac.at/ ims/5oyearsims/ (accessed 13 December 2020). 
Blaukopf, who founded the Department in 1965. Blaukopf was a prominent scholar who is famous for his works on Mahler, ${ }^{2}$ and for the introduction of sociological ideas to the field of music research and an interdisciplinary approach with a focus on what he termed "musical behavior" rather than "music as art". ${ }^{3}$ He considered music broadly as a phenomenon related to any sound production and reception activities, and thus understood that musical sociology should have contributed to the general sociological problems of action and order. Here lies a key difference; it is an epistemological divide typical to the sociological studies of music, and almost absent in the studies of other forms of art. Musical sociology has always been more than a sociology of one form of art, and its ambitions were more profound. This is what may attract the attention of other sociologists and theoreticians to the music sociological scholarship.

Before proceeding to the overview of the contributions, I would like to present a brief reminder of an important theoretical distinction between musical sociology and the sociology of music. The distinction can be framed as follows; there is a problematic preposition "of" which implies that there is a particular aspect of an object, which in the case of music is its social nature that sociology should study. The key problem with the sociology of music has been its reductionism of music to the social conditions of its production and reception. This problem has been widely discussed since the institutionalization of the sociology of music as a discipline, i.e., debates in academic journals, conferences, and books have been dedicated to this problem. ${ }^{4}$ One of the ways to go beyond the reductionist perspective is to focus on the musical work itself, since it embodies the specificity of the musical experience and practice. ${ }^{5}$ An additional suggestion is to reconsider the foundations of the discipline, and to see the sociological studies of music in a general sociological way. It implies the focus will shift to how music (and other arts) contributes to social order and shape social actions. This method was proposed by Tia DeNora, Antoine Hennion, and other scholars. In this aspect, these scholars do not contribute to the sociology of music (the industry, organizations, production and reception, etc.) but to musical sociology, that is, a general sociology that focuses on music as a unit of social order and system of social action. In this perspective, there is a clear emphasis on the processes of music creation, its perception, and on the way music mediates social action. Consequently, the methodology proposed in accordance with this theoretical perspective is a close and detailed observation of actions and actors (similar to ethnographic and ethnomethodological ways to follow what actors do, and how they interact).

Of the nine chapters, four contain theoretical contributions. These chapters are written by Tia DeNora, Antoine Hennion, Howard S. Becker, and Peter J. Martin, all of whom are famous for their studies in music sociology and the sociology of music.

2. Blaukopf K. (1973) Gustav Mahler (transl. P. Hamburger), New York: Praeger Publishers.

3. Blaukopf K. (1992) Musical Life in a Changing Society: Aspects of Music Sociology (transl. D. Marinelli), Portland: Amadeus Press.

4. E.g.: Hennion A., Grenier L. (200o) Sociology of Art: New Stakes in a Post-Critical Time. The International Handbook of Sociology (eds. S. Quah, A. Sales), London: SAGE, pp. 341-355.

5. E.g.: Zembylas T. (ed.) (2014) Artistic Practices: Social Interactions and Cultural Dynamics, London: Routledge. 
The contribution by Tia DeNora is the most systematic one. It is a theory-oriented study of how music works as "a medium of social ordering, a dynamic and powerful ingredient of social life" (p. 134). Starting with the discussion of the dualities in music sociology-music vs. society, micro vs. macro, subject vs. object-DeNora shows that these dichotomies are no longer relevant since they reproduce older theoretical frameworks of the sociology of music. Newer frameworks take the music's specificity and focus on the emergent nature of music experience into account. The shift towards a more nuanced approach enables the integration of music sociological findings into music therapy practice. DeNora provides an example from her research practice of how a specific musical practice can enhance the human experience and reframe the situation during therapy sessions. DeNora argues that music sociology understood and practiced in this way can claim to contribute to general sociological theory. She wrote that "the study of what can be done with music points us to a new way of pursuing sociology's core questions and one that follows culture as it gets into action, emotion and perception (the 'internal' aspects of sociation) in ways that make our worlds and the realities that are about them" (p. 134).

Antoine Hennion reflects on his theoretical and methodological trajectory of building up "a sociology of art that is far removed from today's reigning scientism-a sociology of art that ensures it is equal to the works produced, and especially to what those works call for: the worlds whose possibility they affirm" (p. 42). Hennion says he is not as interested in doing music sociology as in doing sociology with music. To explain what he means, he revisits his notion of mediation and reveals the theoretical influences of Michel de Certeau and Louis Marin on his studies. Hennion shows how he came up with the idea that returning to musical work does not mean the return to the music as an object. Instead, it suggests seeing music as an activity, literally as doing. For Hennion, a musical object is to be unfolded and can be only be grasped in the process of performing; he wrote that "We have to actively make the objects of our pleasure emerge in all their differences and make ourselves aware of those differences" (p. 50). To illustrate the way it happens empirically, he discusses two cases: improvisation in jazz music, and the auto-ethnography of singing lessons. Both cases support his main argument that musical work is something unstable and needs "to-be-done" in order to be treated as music. In this respect, his cases serve as insights on how action is organized and social order emerges.

Then, Howard Becker shares his personal reflections of his own contribution and implications of music scholarship. In particular, he pays attention to the idea of musical language. In his typical straightforward manner, he argues that the main problem of music sociology is that often the outcomes of socio-musicological studies are either too sociological or too musicological. In the former case, therefore, the studies do not require any musical competencies on behalf of the readers, while in the latter case, sociologists usually should have some musical background in order to understand the technical language of music. Sociologists face the problem of a popular presentation of their results to a wider audience which may lack such knowledge. Becker continues, writing that "Musicians talk about music in a language quite divorced from common language: special words for the physical and aural objects they use to make music, and for the sounds, and the kinds 
of sounds they make when they're "making music"' (p. 96). He argues for the importance of possessing technical knowledge by referring to two research cases. The first case is his own study of how jazz musicians can play together without rehearsals or even knowing each other. To answer the question, Becker and his colleague Robert Faulkner carried out auto-ethnographic research, discovering that the answer was that the players should be aware of the part of the song that is played and the time signature, while the rest can be grasped in practice and through conventions. The second case that shows the benefits of musicological knowledge is an ethnomusicological study by Simha Arom who researched the music of the Ngbaka, an ethnic group from the Central African Republic. In order to lay the foundations for the emergence of the national music museum, he recorded folk music, particularly versions of the same song performed by different people. Through the ethnographic and musical analysis of the variety of the performance of the same song, he was able to theoretically reconstruct the musical practice of the Ngbaka. As shown previously, the use of the technical language of music and the ability of ethnographers to look into it along with the ability to master it contributes much to the understanding how music works from a sociological perspective.

The contribution of Peter J. Martin goes into the exploration of the digitization of music, and reflects on the theoretical and research perspectives of "new musicology" and popular music studies. The "new musicology" emerged in the 1980s, and, as Martin puts it, kept some of the assumptions of the old musicology by being mostly preoccupied with decoding the meaning of musical works, their social and cultural significance, and the linear understanding of how society impacts music. These assumptions were challenged both by Kurt Blaukopf and other popular music scholars who focused on the uses of music in everyday life, and the variety of musical forms and genres. For Martin, it is important that music sociology will be able to consider the processes of digitalization through popular music studies, a key challenge for understanding the role of music nowadays.

The next group of papers consists of the contributions that apply the notions of contemporary sociology to the realm of music, and therefore are more concerned with the sociology of music rather than music sociology.

The essay of Alfred Smudits relates music sociology to the times of "mass modernity", a term he introduces to describe the era between the end of WWII and the fall of the Berlin Wall. According to Smudits' views, music sociology has always fallen behind the general sociological situation, and in order to keep its relevance it "has to be aware of the new challenges emerging from the latest socio-cultural and media developments" (p. 19). Among the many changes that became important in the era after "mass modernity", he mentions the increasing role of technologies in the recording and production industries (along with the popularity of listening to music via smartphones), the transformation of the economic and symbolic values of music due to a sharing economy and the increase of the role of digital distribution channels, the emergence of local scenes that exist along with the global musical scene, etc. For Smudits, if the sociology of music wants to keep its relevance, it should "not only need to have a broader knowledge of sociology, but also of neighboring disciplines, including—not least—musicology" (Ibid.). 
The next contribution is a review essay by Marie Buscatto that is dedicated to the way gender still matters in the field of music. She identifies several domains of possible research: social stereotypes regarding gender and musical genres, social networks in the musical fields that are generally considered to be male-dominated, the role of families in the musicians' careers, public regulation and institutional frameworks that guides the operation of the field, and, finally, the marginal segments of the field where gender may be a source for action. Yet, a significant focus on gender issues in the field of music production, as Buscatto notes, may lead to the neglect of other aspects (such as race, age, class, etc.) and "to over- interpret the extra-musical realities" (p. 75).

The account of how cosmopolitan culture is reflected in music belongs to Motti Regev. He follows the idea of cosmopolitan bodies that are inscribed with a cosmopolitan aesthetic culture. For Regev, it is pop-rock music that enables the global transmission of cosmopolitan culture on the corporeal level. This study may be considered as a way to address musical specificity with a focus on the bodily level, but since the paper lacks specific examples of how pop-rock music is embodied in practice, the term "cosmopolitan bodies" is often used in a metaphorical and general way. After the analysis of the typical features of pop-rock music, Regev concludes that "we may assert that pop-rock music has constituted its listeners as aesthetic cosmopolitan bodies, that is, as bodies inscribed with musico-aural knowledge that affords a sense of being local and translocal at the same time" (p. 90).

The last chapter by Christian Kaden takes a particular place in the volume. It is a historical overview of the development of music sociology in East Germany and its contexts. Kaden describes the informal network of scholars who worked in the field of musicology at that time, and reveals their relations with other fields of knowledge (cybernetics, system theory, etc.). This essay also reflects on the contemporary transformation of academic practices, for as Kaden writes, "Today there is no real will for cooperation in German musicology. And the discipline as a whole is governed by the feudalist tendencies of establishing domains of scientific power" (p. 155).

The celebratory idea of the volume implies an inevitable peculiarity: the volume may seem unbalanced because conceptual reflections go along with personal and review essays but often fail to correspond to each other. Alfred Smudits, who served as an editor, writes that the volume is "selective and therefore intends to highlight certain themes" (p. 2). It also means that it is more oriented to a specific national tradition of music sociology - the German tradition, probably one of the most fruitful in terms of finding common ground between the sociological thought on music and musicology.

Additionally, three features characterize the volume. First, though the anthology addresses key issues of contemporary studies of music from a sociological standpoint, it clearly follows the socio-musicological perspective theoretically, and therefore almost completely neglects the studies of the consumption of music in a more conventional way. Second, the papers in this volume do not look at specific musical pieces, and thus do not consider them as a way to understand social order. Turning towards the musical object in this respect means to look at its effects, and to what Adorno metaphorically called "physi- 
ognomics" in his contribution to the Radio Project. ${ }^{6}$ Alternatively, American cultural sociology would have focused on iconic musical objects. Third, the political dimension and the contribution of arts and music to the emergence of political order is overlooked. This may sound surprising because politics is one of the domains where social order comes from.

These features may be seen as limitations or even as drawbacks of the volume, yet the book shows that music sociology is well-established and specified in terms of theory. However, its agenda is still not articulated on the level of empirical research, and is often replaced by more conventional cases of empirical research. In this regard, empirical music sociology is still a promise.

\section{Новые маршруты и старые надежды музыкальной социологии}

\section{Наиль Фархатдинов}

$\mathrm{PhD}$, старший научный сотрудник, Центр фундаментальной социологии, Национальный исследовательский университет «Высшая школа экономики»

Адрес: ул. Мясницкая, д. 20, г. Москва, Российская Федерация 101000

E-mail: nfarkhatdinov@hse.ru

Рецензия: Alfred Smudits (ed.), Roads to Music Sociology (Wiesbaden: Springer, 2019).

6. Adorno T. (2006) Current of Music: Elements of a Radio Theory, Frankfurt: Suhrkamp. 